\title{
The Elements of Chinese Traditional Culture Embodied in the Advertisement Design
}

\author{
Yi Chen \\ Zhuhai College of Jilin University \\ Zhuhai Guangdong 519041 China
}

\begin{abstract}
Commercial advertisement is the advertisement that has close connection with commodity, commercial activity, commercial category. This paper aims to solve the problem of the lack of traditional cultural features in modern commercial advertising. By analyzing the development of commercial advertisement, the author studies and discusses the characteristics of color and shape in the aesthetic implication of different elements in traditional culture. This paper analyzes the application of colors and shapes of different elements in traditional culture in modern advertisements, and expounds the influence they bring to modern advertisements.
\end{abstract}

Keywords-Traditional culture; Advertising design; Analysis and research

\section{INTRODUCTION}

Commercial advertisement develops in an all-round way under the development trend of world economic integration. Cultural diversity and diversity continue to extend. Homegrown traditional art can take a big hit. It is a fact that we do not need to dispute that the level of commercial art in our country has been greatly improved. The comprehensive and rapid development of the global economy has changed the traditional painting methods and people's aesthetic taste. This has a certain influence on the style of commercial advertisements and the way of painting, and people's aesthetic characteristics are also changing. Although the current commercial advertisement has created completely different aesthetic characteristics from the time of manual painting by means of the mixture of various elements, gorgeous colors and diversified types.

\section{TRADITIONAL CULTURE AND ADVERTISING ART}

\section{A. Overview of Chinese traditional culture}

Chinese culture is a widely spread form of culture. It is mainly represented by the related cultural customs and performing music of the traditional Chinese nation -- the Han nationality. It is also known as Chinese culture or Chinese civilization. Chinese culture covers everything from Chinese characters, calligraphy and painting, music and other cultural and art forms to ethnic customs and religious beliefs. Due to the influence and communication ability of Chinese culture, many countries in East Asia and Southeast Asia are also influenced by Chinese culture. In recent years, Confucius institutes in Japan, Myanmar, Indonesia and other places, as well as cultural concepts such as "Tang Style" and
"Chinatown", which have been popular all over the world, are sub-branches of Chinese culture. They are radiated by Chinese cultural tradition and show the survival, thinking, aesthetic and enlightenment characteristics of the Chinese nation. Gradually became the representative of Chinese civilization in the new era. The development of Chinese culture and forming after a long time, from the ancient to the modern transformation process is thousands of years of Chinese culture to enrich and expand the historical roots, emerge in the process of excellent characters such as Confucius and Zhuangzi, Guan Zhong and good ideas are the characteristics of the Chinese nation culture, is also important for Chinese culture to the development of the reality.

Traditional culture refers to traditional culture in a popular way, with the emphasis on culture. The two corresponding concepts are contemporary culture and foreign culture. The content of traditional culture includes the sum of all kinds of material, institutional and spiritual cultures in each era entity and consciousness. For example, national costume, national custom, ancient poetry and classics, national spirit and so on, especially is the cultural heritage we often say.

Traditional culture is the combination of historical custom, ethical philosophy, art and system, and the sum of various cultural phenomena in material life and spiritual life. Historically, people's traditional culture and development process is the progress of history and the progress of human generations, with its special significance and basic spirit.

The traditional culture has the material, also has the intangible. They appear in the field of culture, which is not only externalized in people's lifestyle, customs, psychological characteristics, aesthetic character, values, but also internalized in the transmission of national spirit from generation to generation.

\section{B. The value of the application of traditional culture in advertising design}

Traditional culture is the witness of the long history of the Chinese nation and the cultural trait of the Chinese nation. In recent years, the application of traditional culture in society has become more common, and the visibility of traditional cultural elements and social life has become higher and higher. In the new media era, advertising, as a means of media, has also been well developed with the visual cognitive power and appeal of traditional culture. In the advertising industry with international development, the combination of traditional cultural elements and advertising design can provide distinctive cognitive power. 
For example, in the international advertising art competition, the works won by China are often presented with the main elements of traditional culture as the carrier. On the premise of increasing international influence of Chinese culture, advertising design combined with traditional culture is a trend, which can further enhance the international influence of Chinese culture. Therefore, it is a win-win approach to integrate traditional cultural elements into modern advertising design.

\section{THE EMBODIMENT OF TRADITIONAL CULTURAL ELEMENTS IN ADVERTISING DESIGN}

\section{A. Use traditional cultural elements to achieve different advertising creativity and modeling}

\section{1) Abstract application of traditional cultural elements in advertisements}

In his book "abstraction and empathy", Willinger talked about the primitive man's "abstract impulses". He believed that the primitive man had the strongest impulse to integrate the external things such as nature into his mind, and to carry out abstraction and purification, making all unreasonable things become reasonable and finally expressing his thoughts through extremely abstract creation. Abstract modeling is a technique of expression that uses a method of removing visible natural phenomena, which is expressed purely by means of form. More emphasis on the image of the inner image temperament on god. For example, traditional Chinese cultural elements -- New Year paintings have the word "longevity". In this word, "eight immortal birthday star" is integrated, and a large number of conifers, peaches, cranes and other things that represent longevity. Modern ads need to be abstract, these representational content into abstract geometrical modeling, this process is very complex, the integrated use of a variety of methods, from the structure, color and other aspects to obtain, with a final point, line, surface geometry and other visual elements are combined, to form the commercial subject content, this is not what we say through observation and earnest can be done, the elements involved in a lot of use, include all sorts of profound cultural thoughts. Therefore, the changed advertisement can not only show the connotation of national culture, but also have formal beauty, which contains the abstract creation characteristics of the original art.

In practical applications, such as the advertising design of Tmall website in New Year shopping festival, the use of "words hidden paintings" style. It is verified that this comes from the ancient Chinese folk word "flower and bird". Based on Chinese characters, "flower and bird" integrates flowers, birds and words into one. Dancing and moving, it reflects each other and is popular with both refined and popular tastes. It was once praised by "officials" and is more popular with the public. It spread to Japan, Korea, and Southeast Asia. Such traditional cultural elements can be preserved in the folk for a long time, mainly because it means auspicious and often brings a happy atmosphere. With the application of multimedia technology, the commercial advertising in the composition of the picture borrows the method of traditional art design skillfully, making the whole picture more substantial, there is no white space, patchwork, clear main and secondary, solid sense, not tedious, and give people a multi-level aesthetic feeling, that is, no loss of modeling, no loss of connotation. Type must act the role of, act the role of must suit, show thick adornment flavor.
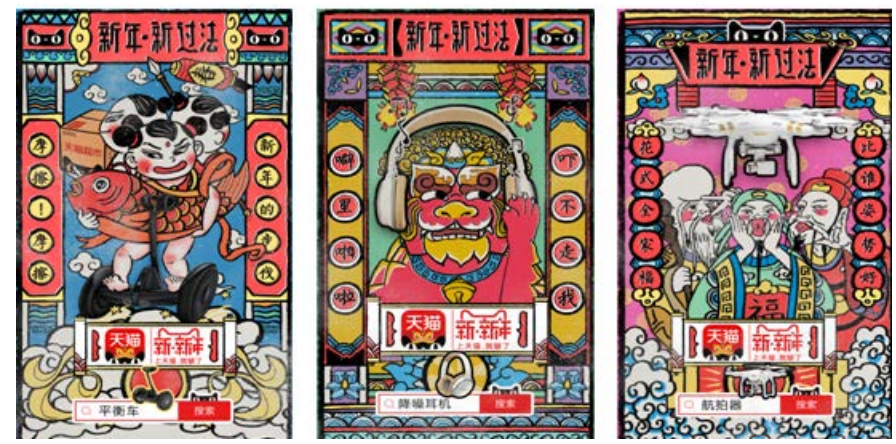

Fig. 1. Embodiment of Chinese traditional cultural elements in advertising design

\section{2) Application of traditional color elements in advertising} design

In the current artistic creation, the color in the expression time often has the tension. In visual transmission, color is one of the most critical elements, which plays a preconceived role. When carrying on transmission, people's first feeling is brought by color mostly. With the wide application of traditional elements in commercial art design, this feeling is more intense. Studies have shown that text and pictures always lag behind color in the process of information transmission. Therefore, in the process of color design, the characteristics of New Year paintings in different regions should be considered, and the people in this region should respect their aesthetic value of color. Only in this way can we be flexible in the design process Only in this way can commercial advertisements conform to the aesthetics of the public and promote consumption. Therefore, in the commercial advertising art design, we should focus on the color and profound connotation of traditional New Year paintings.

Traditional cultural elements have various colors. In addition to the basic 7 colors, some decorative colors with high visual impact effect, such as green blue, red blue and yellow purple also appear in the modern advertising design. In the commercial, whether the color is used properly, directly feel the final success or failure. In many cases, designers have adopted the creation mode of strong contrast in order to attract more attention, while the creation mode of intense contrast favored by traditional Chinese New Year painting artists and current commercial advertising designers is very similar. The most remarkable feature of traditional Chinese New Year paintings is their strong contrast. Through a series of contrast, they are developed from various aspects such as light and shade, area and so on, and finally bring a very strong feeling to the audience.

When applied to advertisement design, the color of traditional culture element reflected intense folk interest. Bright and strong colors, such as black, yellow, red, Dan, green, blue, purple and so on. Color exquisite, registering and tinted effect less heavy and complicated and bright color soft hard reasonable collocation of color, at the same time there is a proverb, such as "soft hard color collocation of color, color is 
not a single" (soft color refers to the relatively weak, and the color of the powder, hard color is black, dark blue, green, red and other color), "red, yellow, color.", "red should not be collocation purple, purple should not be black, and yellow collocation should match the green, green with red" and so on, all reflect the Chinese folk special preference for color collocation, color class is not much, tie-in effect is strong and warm. Modern advertising absorbs the experience of color matching in traditional cultural elements and combines traditional characters.

In addition, some cultural elements with large symbolic colors are also applied in the advertising design, such as the five elements. The five colors and five elements have more profound meanings in Chinese history and culture, and contain profound cosmology and social morality. "Five colors" has always been regarded as a positive color, with the same divine nature as the five elements, and associated with people's social status. It can be said that throughout the feudal period, the application of colors was always influenced by the theory of Yin and Yang and the thought of rulers. Therefore, 'five colors"refers to the five colors of green, red, yellow, white and black, which are also the concept of primary colors in the Chinese concept. (table 3.2) in the process of designing advertisements, we can have a deep understanding of the symbolic colors of colors and realize the use of colors to express ideas, which makes the audience's situation and the symbolic colors resonate, and then present the creation theme in a more three-dimensional and comprehensive way.

\section{COUNTERMEASURES TO PERFECT THE APPLICATION OF TRADITIONAL CULTURAL ELEMENTS IN ADVERTISING DESIGN}

\section{A. Attach importance to cultural inheritance and expand the application of traditional cultural elements in advertising design}

Cultural heritage is the important path of the Chinese nation's rich history and culture of 5000 years of civilization give us large databases, the Confucian culture, regional culture, folk culture, red culture, socialist culture is associated with development of Chinese nation culture of different forms, some laid the basic values and social ideology in our country, some determine social style and features, the way of the world; Some are specific cultural types formed in specific historical and cultural backgrounds. It is of certain practical significance to perfect the contemporary inheritance of traditional culture in advertising design. Meanwhile, it is necessary to strengthen the application of traditional cultural elements in new media advertising and improve its application space. In 2012, large scale of China's online advertising market, the type is various, including video patch advertising, brand graphic ads, electricity (including the effect of display and advertising), search engine advertising (including keyword advertising and advertising, etc.), advertising, classified advertising text chain, information flow, advertising and other forms of advertising, such as navigation ads, E-mail, etc.), etc. Internet advertising is through the Internet media advertising, and television, newspapers, magazines, radio, outdoor and other traditional advertising, compared with the bidirectional interaction, quantifiable effect, and put in the data can be accumulated reuse, users pay attention to four aspects, such as advantages, these advantages also determines its can be better and the integration of traditional culture elements, improve the application of the traditional culture elements in advertising design.

\section{B. Strengthen the advertising abstraction of traditional cultural elements}

Although there are many types of traditional cultural elements, it still needs some artistic processing and extraction in the application of advertising design. At present, commercial development of traditional cultural elements has not yet formed scale, and cultural forms such as folk paper cutting, batik and New Year painting as well as some cultural elements embodied in intangible cultural heritage have not been tried in commercial advertising design. In the future, we can strengthen the teaching and practical research on the application of traditional culture to advertising design, actively seek inspiration from traditional cultural forms, strengthen the advertising abstraction of traditional cultural elements, and better apply them to design.

\section{CONCLUSION}

Different consumers and the demand side will have a variety of needs. The commercial advertisement uses theme, shape and color to add traditional cultural visual elements as its innovative content: (1) In the modeling style, traditional cultural elements are applied to be medium, simple and gentle, realistic and exaggerated, witty and solemn, making a commercial work achieve harmonious coexistence. (2) Apply the expression technique of "high purity and strong contrast" of traditional cultural elements to the advertising design. Through the analysis of this paper gave a new idea of advertising design.

\section{REFERENCES}

[1] Dou Zhizheng. Application study of Chinese traditional graphics in real estate graphic advertisement design [D]. Yanshan university,2012.

[2] Yin Chengyun. Application of traditional Chinese aesthetic cultural elements in modern advertising [D]. Hunan normal university,2017.

[3] Wei Linhong. Reflection of Chinese traditional cultural elements in modern product design -- thoughts and Suggestions on products with the shape of Fujian old building [J]. China packaging industry,2013(10):56+58.

[4] Dong Minliang. Research on the application of Chinese traditional cultural elements in advertising design -- taking in $\mathrm{k}$ and wash elements as an example [J]. Modern decoration (theory),2015(03):95.

[5] Wu Haibo. Discussion on the application of Chinese local traditional cultural elements in real estate advertising design [J]. Design,2015(15):150-153.

[6] Li Jiaheng. The embodiment of Chinese traditional cultural elements in graphic design [J]. Chizi (upper middle school),2015(22):97. 